Rothmaler W. 1995. Exkursionsflora von Deutschland. Band 3. Gefäßpflanzen: Atlasband. s. 441. Auflage 9. G. Fischer, Jena - Stuttgart.

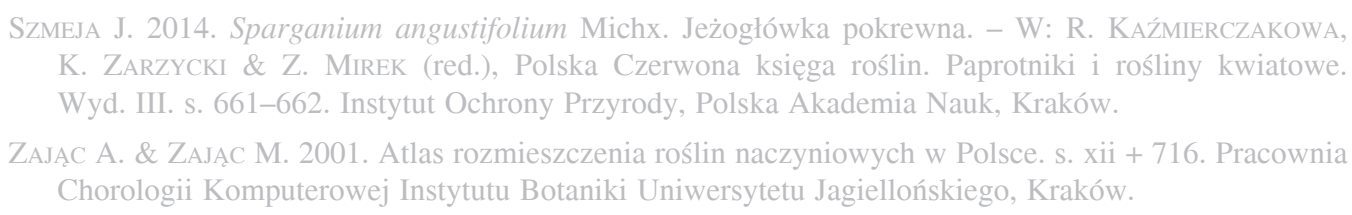

Anna Koczur, ul. Kmietowicza 1/4,30-092 Kraków, Polska; e-mail: koczur.anna@yahoo.com Anna Maria OcIEPA, FUP Kościelisko, skrytka nr 17, 34-511 Kościelisko, Polska; e-mail: amociepa@interia.pl

Wptynęto: 23.03.2020 r.; przyjęto do druku: 09.11.2020 r.

DOI: https://doi.org/10.35535/ffgp-2020-0060

\title{
Nowe stanowiska Orchis pallens (Orchidaceae) na Wyżynie Śląskiej
}

Rodzaj storczyk (Orchis L.), liczy 21 gatunków, występujących w Europie, Azji i Afryce północno-zachodniej. W Polsce stwierdzono cztery z nich (CHASE i in. 2015; WCSP 2020).

Orchis pallens L., storczyk blady, to bylina o wysokości $20-35 \mathrm{~cm}$, z 4-6 podługowatojajowatymi liśćmi u nasady łodygi. Ma bladożółte kwiaty, tworzące w kwietniu lub maju jajowate kwiatostany (ZAJĄC \& FIEDOR 2014). Kwiaty storczyka bladego, podobnie jak w przypadku innych przedstawicieli rodzaju, należą do tzw. kwiatów zwodniczych - wabią owady zapylające, lecz nie ofiarują im pokarmu (CLAESSENS \& KLEYnEN 2011). Ponadto VöTH (1982) wskazał zależność pomiędzy budową ostrogi kwiatu O. pallens, a budową kwiatu groszku wiosennego (Lathyrus vernus), opartą na zasadach tzw. mimikry batesowskiej. Podobieństwo to zwiększa szansę wizyty zapylacza (głównie trzmielowate) na zwodniczym kwiecie storczyka w okresie przekwitania nektarodajnych kwiatów groszku. Zasięg gatunku obejmuje południową oraz środkową część Europy od Pirenejów po Kaukaz (BERNACKI i in. 2008; ZAJĄC \& FIEDOR 2014). Storczyk blady jest gatunkiem górskim reglowym (ZAJĄC 1996), w Polsce narażonym na wyginięcie. Główne zagrożenia dla tego gatunku, to zarastanie i zalesianie muraw oraz w mniejszym stopniu bezpośrednie niszczenie stanowisk np. przez motory krosowe (ZAJAC \& FiEdor 2014; KAźMIERCZAKOwA $\mathrm{i}$ in. 2016). Występuje w grądach (Tilio-Carpinetum), zaroślach (Prunetalia) i murawach kserotermicznych.

W Polsce Orchis pallens został odnotowany na ponad 30 stanowiskach, zlokalizowanych głównie na Pogórzu Cieszyńskim oraz w Karpatach Zachodnich (Dolina Dunajca) - obecnie występuje na 23 z nich (ZAJĄC \& FIEDOR 2014). Jak dotąd, najdalej wysunięte na północ stanowiska tego gatunku w Polsce były położone na Wyżynie Miechowskiej (MATYjaszKiEWICZ 1990; BinKIEWICZ 2010). 


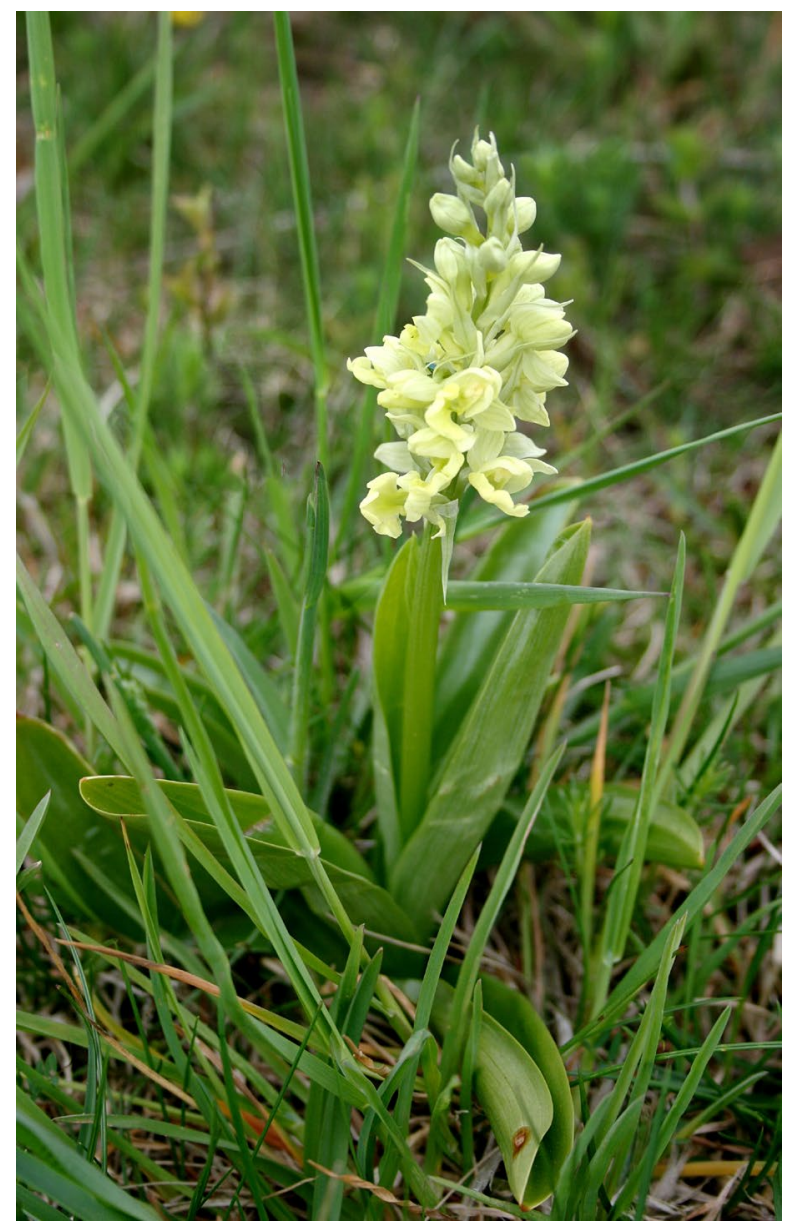

Ryc. 1. Orchis pallens na nowym stanowisku w rezerwacie Ligota Dolna (fot. Ł. Folcik)

Fig. 1. Orchis pallens in the new locality in the Ligota Dolna Reserve (photo by Ł. Folcik)

W trakcie badań terenowych, prowadzonych w ramach rozprawy doktorskiej pt. „Antropogeniczne przemiany flory roślin naczyniowych Chełmu (Wyżyna Śląska) ze szczególnym uwzględnieniem zjawiska wymierania gatunków" (FOLCIK 2019), zostały stwierdzone dwa nowe stanowiska storczyka bladego. W sieci kwadratów ATPOL (ZAJĄC 1978; ZAJĄC \& ZAJĄC 2001) są one zlokalizowane $\mathrm{w}$ jednostkach kartogramu $2 \times 2 \mathrm{~km}$ o symbolach CF1643 i CF2604. Poniżej zamieszczono zdjęcia fitosocjologiczne, wykonane w granicach powierzchni, na których występuje ten gatunek. Nazwy łacińskie gatunków przyjęto za Mirkiem i in. (2002).

Pierwsze stanowisko położone jest na południe od miejscowości Ligota Dolna (gmina Strzelce Opolskie, województwo opolskie), w granicach rezerwatu przyrody o tej samej nazwie. Cała populacja skupia się na obszarze płaskiej wierzchowiny i zajmuje powierzchnię około $220 \mathrm{~m}^{2}$. W 2014 r., kiedy zaobserwowano ten gatunek po raz pierwszy, liczyła 49 osobników, w tym 34 kwitnące. Do 2019 r. liczby te ulegały 
niewielkim wahaniom (za wyjątkiem 2018 r., kiedy nie obserwowano okazów kwitnących). Orchis pallens rośnie tu w kadłubowej murawie kserotermicznej o charakterze pośrednim między zespołami Origano-Brachypodietum pinnati oraz Origano-Vincetoxicetum hirundinariae ( $\mathrm{Zdj} .1)$.

Zdj. 1. Data: 21.04 .2014 , lokalizacja: $50^{\circ} 28^{\prime} 54,6^{\prime \prime} \mathrm{N} 18^{\circ} 07^{\prime} 25,9^{\prime \prime} \mathrm{E}$, wysokość nad poziomem morza: $322 \mathrm{~m}$, nachylenie $0^{\circ}$, zwarcie w warstwach: B $<5 \%$, C 100\%, powierzchnia zdjęcia $100 \mathrm{~m}^{2}$. B: Ligustrum vulgare +, Rhamnus cathartica +, C: Brachypodium pinnatum 3, Arrhenatherum elatius 2, Cerastium arvense 2, Festuca rupicola 2, Orchis pallens 2, Vincetoxicum hirundinaria 2, Avenula pubescens 1, Euphorbia cyparissias 1, Fragaria viridis 1, Galium verum 1, Origanum vulgare 1, Achillea collina +, Acinos arvensis + , Barbarea vulgaris + , Clinopodium vulgare + , Crataegus sp. + , Helianthemum nummularium subsp. obscurum + , Myosotis ramosissima + , Polygala comosa + , Potentilla heptaphylla + , Ranunculus bulbosus + , Salvia pratensis + , Sanguisorba minor + .

Drugie stanowisko (oddalone około $1,5 \mathrm{~km}$ na południe od pierwszego), zlokalizowane jest we wschodniej części wsi Oleszka (gmina Zdzieszowice). Odnotowano tu cztery kwitnące okazy. Storczyk blady występował w zarastającej murawie Koelerio-Festucetum rupicolae, wykształconej na obrzeżach niewielkiego sadu czereśniowego. Od 2015 r. gatunek nie był w tym miejscu obserwowany. Skład florystyczny zbiorowiska przedstawia zdjęcie fitosocjologiczne:

Zdj. 2. Data: 25.04 .2014 , lokalizacja: $50^{\circ} 28^{\prime} 07,3^{\prime \prime} \mathrm{N} 18^{\circ} 07^{\prime} 39,8^{\prime \prime} \mathrm{E}$, wysokość nad poziomem morza: $260 \mathrm{~m}$, nachylenie $2^{\circ}$, ekspozycja SSW, zwarcie w warstwach: C 70\%, powierzchnia zdjęcia $25 \mathrm{~m}^{2}$. C: Festuca rupicola 3, Arrhenatherum elatius 2, Fragaria viridis 1, Galium verum 1, Achillea collina + , Agrimonia eupatoria + , Carex flacca + , Centaurea scabiosa + , Coronilla varia,+ Euphorbia cyparissias + , Orchis pallens + , Potentilla heptaphylla + , Salvia verticillata + , Sanguisorba minor + .

Krajowe stanowiska Orchis pallens wyznaczają jego północną granicę zasięgu. Nowo odkryte populacje należą do najbardziej wysuniętych na północ oraz zachód w Polsce - storczyk blady przybył tu prawdopodobnie przez Bramę Morawską (BRZYSKI 1961). Ponadto są to pierwsze notowania tego gatunku na obszarze województwa opolskiego, a także Wyżyny Śląskiej. Największym zagrożeniem dla storczyka bladego na nowych stanowiskach jest zarastanie muraw. W celu zachowania tego gatunku wskazany jest monitoring jego populacji, a w razie konieczności zastosowanie zabiegów ochronnych, takich jak odkrzaczanie lub koszenie.

Summary. New localities of Orchis pallens (Orchidaceae) in the Silesian Upland. The paper presents two new localities of Orchis pallens in the Chełm mesoregion (Silesian Upland, S Poland), found in 2014 in the vicinity of Ligota Dolna and Oleszka villages in Opole Province. The species occurs in overgrowing xerothermic grassland communities (Koelerio-Festucetum rupicolae, Origano-Brachypodietum pinnati, Origano-Vincetoxicetum hirundinariae). The populations consisted of 4 flowering individuals in Oleszka and 49 (34 flowering) in Ligota Dolna, with slight seasonal fluctuation. The main threats to the newly found localities of Orchis pallens are succession processes in xerothermic grassland communities. Active nature protection employing measures such as mowing or shrub removal is required.

\section{LITERATURA}

Bernacki L., Pacyna A. \& Nejfeld P. 2008. Storczyk blady Orchis pallens L. - W: Z. MireK \& H. PięKoŚ-Mirkowa (red.), Czerwona księga Karpat Polskich - rośliny naczyniowe, s. 483-485. Instytut Botaniki PAN, Kraków. 
BINKIEWICZ B. 2010. Nowe stanowisko Orchis pallens (Orchidaceae) na Wyżynie Miechowskiej. - Fragmenta Floristica et Geobotanica Polonica 17(2): 404-406.

BRZYSKI B. 1961. Orchis pallens i inne interesujące gatunki w dolinie Dunajca koło Wojnicza (pow. Brzesko). - Fragmenta Floristica et Geobotanica 2(7): 317-326.

Claessens J. \& Kleynen J. 2011. The flower of the European orchid. Form and function. s. 440. Jean Claessens \& Jacques Kleynen, Voerendaal.

Chase M. W., Cameron K. M., Freudenstein J. F., Pridgeon A. M., Salazar G., van den Berg C. \& Schuiteman A. 2015. An updated classification of Orchidaceae. - Botanical Journal of the Linnean Society 177: 151-174.

FolCIK Ł. 2019. Antropogeniczne przemiany flory roślin naczyniowych Chełmu (Wyżyna Śląska) ze szczególnym uwzględnieniem zjawiska wymierania gatunków. Msk. Rozprawa doktorska wykonana w Katedrze Botaniki i Ochrony Przyrody Wydziału Biologii i Ochrony Środowiska Uniwersytetu Śląskiego w Katowicach.

Kaźmierczakowa R., Bloch-OrŁowska J., Celka Z., Cwener A., Dajdok Z., Michalska-Hejduk D., PAWLIKowski P., SzCZEŚniak E. \& ZiarneK K. 2016. Polska czerwona lista paprotników i roślin kwiatowych. s. 44. Instytut Ochrony Przyrody Polskiej Akademii Nauk, Kraków.

MatyjasZKIEWICZ M. 1990. Orchis pallens L. na Wyżynie Miechowskiej. - Zeszyty Naukowe Uniwersytetu Jagiellońskiego, Prace Botaniczne 21: 141-144.

Mirek Z., Pięroś-Mirkowa H., Zając A. \& ZająC M. 2002. Flowering plants and pteridophytes of Poland. A checklist. - W: Z. MireK (red.), Biodiversity of Poland. 1, s. 442. W. Szafer Institute of Botany, Polish Academy of Sciences, Kraków.

Vӧтн W. 1982. Die „,ausgebortgen” Bestäuber von Orchis pallens L. - Orchidee 31(4): 159-162.

WCSP 2020. Search for Orchis. World Checklist of Selected Plant Families. Facilitated by the Royal Botanic Gardens, Kew. http://wcsp.science.kew.org/ (dostęp: 25.04.2020).

ZAJĄC A. 1978. Założenia metodyczne „Atlasu rozmieszczenia roślin naczyniowych w Polsce”. - Wiadomości Botaniczne 22(3): 145-155.

ZAJĄC A. \& ZAJĄC M. (red.). 2001. Atlas rozmieszczenia roślin naczyniowych w Polsce. s. xii + 714. Nakładem Pracowni Chorologii Komputerowej Instytutu Botaniki Uniwersytetu Jagiellońskiego, Kraków.

ZAJAC M. 1996. Mountain vascular plants in the Polish lowlands. - Polish Botanical Studies 11: 1-92.

ZAJĄC M. \& Fiedor M. 2014. Orchis pallens L. Storczyk blady. - W: R. KAŹMIERCZAKowa, K. ZarZYCKI \& Z. MireK (red.), Polska czerwona księga roślin. Paprotniki i rośliny kwiatowe, s. 783-786. Instytut Ochrony Przyrody Polskiej Akademii Nauk, Kraków.

ZARZYCKI K. \& SZeląG Z. 2006. Red list of the vascular plants in Poland. - W: Z. MiReK, K. ZarZYCKI, W. Wojewoda \& Z. SzeląG (red.), Red list of plants and fungi in Poland, s. 11-20. W. Szafer Institute of Botany, Polish Academy of Sciences, Kraków.

ŁUKASZ FOLCIK, e-mail: lukaszfolcik@gmail.com

ANDRZEJ UrBISZ, Instytut Biologii, Biotechnologii i Ochrony Środowiska, Wydziat Nauk Przyrodniczych, Uniwersytet Ślaski, ul. Jagiellońska 28, 40-032 Katowice, Polska; e-mail: andrzej. urbisz@us.edu.pl

Wptynęto: 12.12.2019 r.; przyjęto do druku: 20.10.2020 r.

DOI: https://doi.org/10.35535/ffgp-2020-0061 